\title{
High prevalence of carriage of $m c r$-1-positive enteric bacteria among healthy children from rural communities in the Chaco region, Bolivia, September to October 2016
}

Tommaso Giani ${ }^{1,2}$, Samanta Sennati ${ }^{1}$, Alberto Antonelli², Vincenzo Di Pilato ${ }^{2}$, Tiziana di Maggio, Antonia Mantella ${ }^{2}$, Claudia Niccolai $^{2}$, Michele Spinicci2 , Joaquín Monasterio ${ }^{3}$, Paul Castellanos ${ }^{4}$, Mirtha Martinez ${ }^{5}$, Fausto Contreras 5 , Dorian Balderrama Villaroel ${ }^{5}$, Esther Damiani 6 , Sdenka Maury 7 , Rodolfo Rocabado ${ }^{8}$, Lucia Pallecchi ${ }^{1}$, Alessandro Bartoloni ${ }^{2,9}$, Gian Maria Rossolini ${ }^{2,10}$ 1. Department of Medical Biotechnologies, University of Siena, Siena, Italy

2. Department of Experimental and Clinical Medicine, University of Florence, Florence, Italy

3. Servicio Departamental de Salud (SEDES) de Santa Cruz, Santa Cruz, Bolivia

4. Servicio Departamental de Salud (SEDES) de Tarija, Tarija, Bolivia

5. Servicio Nacional de Sanidad Agropecuaria e Inocuidad Alimentaria (SENASAG), Ministerio de Desarrollo Rural y Tierras, Santa Cruz, Bolivia

6. Instituto Nacional de Laboratorios de Salud (INLASA), Ministerio de Salud, La Paz, Bolivia

7. Unidad Epidemiología, Ministerio de Salud, La Paz, Bolivia

8. Servicios Generales de Salud, Ministerio de Salud, La Paz, Bolivia

9. Infectious and Tropical Diseases Unit, Careggi University Hospital, Florence, Italy

10. Clinical Microbiology and Virology Unit, Careggi University Hospital, Florence, Italy

Correspondence: Gian Maria Rossolini (gianmaria.rossolini@unifi.it)

Background: The $m c r-1$ gene is a transferable resistance determinant against colistin, a last-resort antimicrobial for infections caused by multi-resistant Gram-negatives. Aim: To study carriage of antibioticresistant bacteria in healthy school children as part of a helminth control and antimicrobial resistance survey in the Bolivian Chaco region. Methods: From September to October 2016 we collected faecal samples from healthy children in eight rural villages. Samples were screened for $m c r-1$ - and $m c r-2$ genes. Antimicrobial susceptibility testing was performed, and a subset of 18 isolates representative of individuals from different villages was analysed by whole genome sequencing (WGS). Results: We included 337 children (mean age: 9.2 years, range: $7-11 ; 53 \%$ females). The proportion of $\mathrm{mcr}-1$ carriers was high (38.3\%) and present in all villages; only four children had previous antibiotic exposure. One or more $m c r$-1-positive isolates were recovered from 129 positive samples, yielding a total of 173 isolates (171 Escherichia coli, 1 Citrobacter europaeus, 1 Enterobacter hormaechei). No $\mathrm{mcr}-2$ was detected. Co-resistance to other antimicrobials varied in $m c r$-positive $E$. coli. All 171 isolates were susceptible to carbapenems and tigecycline; $41(24.0 \%)$ were extended-spectrum $\beta$-lactamase producers and most of them (37/41) carried bla ${ }_{\text {стх }}$ $\mathrm{M}^{\text {-type genes. WGS revealed heterogeneity of clonal }}$ lineages and $m c r$-genetic supports. Conclusion: This high prevalence of $\mathrm{mcr}$-1-like carriage, in absence of professional exposure, is unexpected. Its extent at the national level should be investigated with priority. Possible causes should be studied; they may include unrestricted use of colistin in veterinary medicine and animal breeding, and importation of mcr-1-positive bacteria via food and animals.

\section{Background}

The $m c r-1$ gene is a transferable colistin resistance determinant that was first described among enterobacterial strains isolated from animals and humans in China. The gene encodes a phosphoethanolamine transferase that modifies the colistin target by addition of phosphoethanolamine to the 1' or 4' phosphate group of lipid $A$, which reduces its affinity to colistin $[1,2]$. Discovery of $\mathrm{mcr}-1$ was considered highly alarming, given the role that colistin has recently regained as a last-resort antibiotic for treatment of infections caused by multi-resistant Gram-negative pathogens such as carbapenem-resistant Enterobacterales and Acinetobacter baumannii $[1,3]$.

Subsequent to its discovery, several studies have revealed a global distribution of $m c r-1$, with an overall higher prevalence among Escherichia 


\section{FIGURE 1}

Geographical locations of the surveyed communities and the proportion of $m c r$-1-positive samples, Chaco, Boliva, September-October 2016 ( $\mathrm{n}=8$ communities)

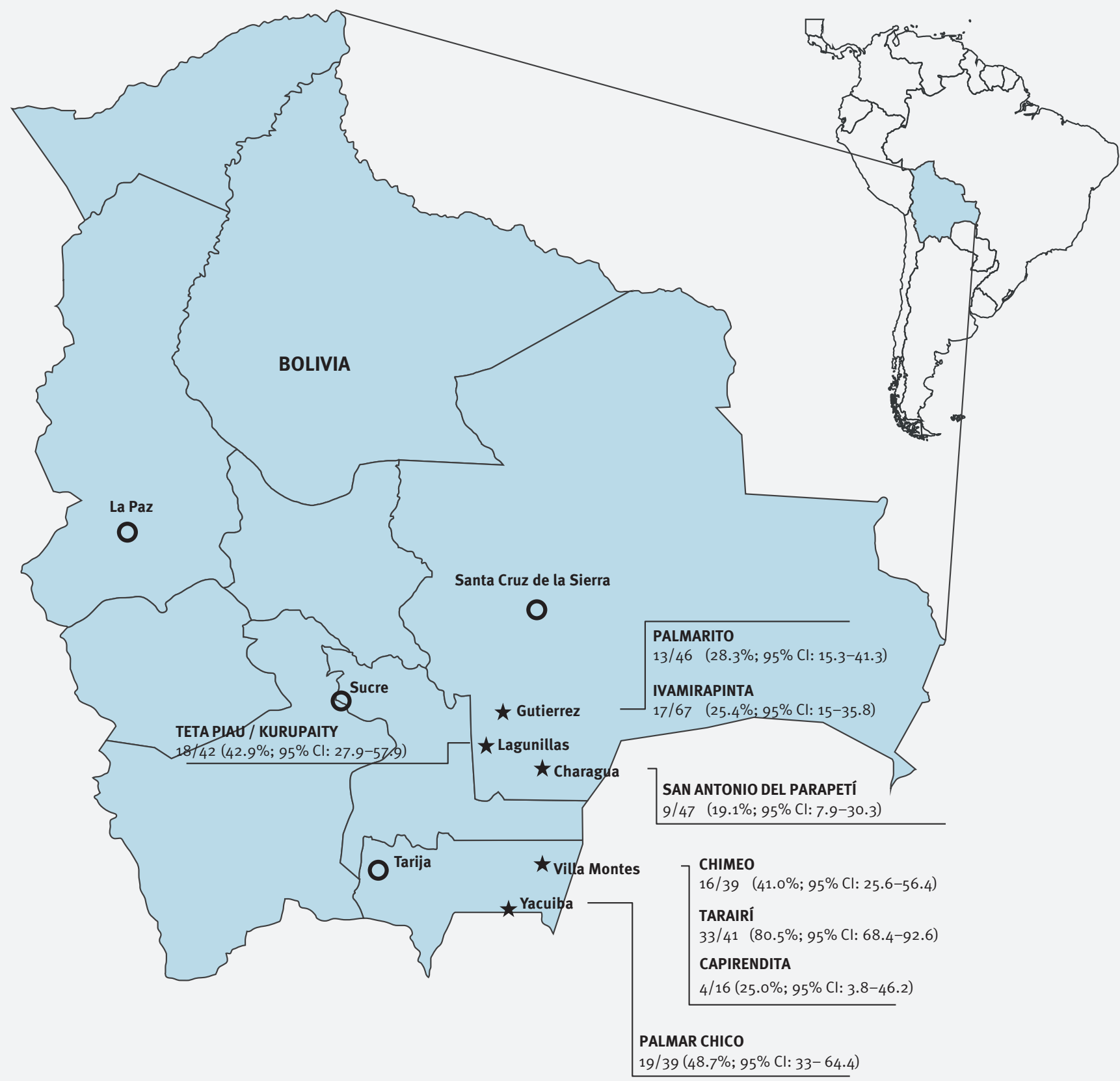

$\mathrm{Cl}$ : confidence interval.

The surveyed communities are located in the Bolivian Chaco, in rural areas of five municipalities (indicated with stars). For each community, the proportion of mcr-1-positive samples versus the total number of collected samples is reported, along with $95 \%$ CI. Major Bolivian cities are indicated by circles.

coli and Salmonella enterica, and occasional occurrence in other enterobacterial species. Most mcr-1-positive strains were of animal origin, and farm animals were identified as the principal reservoir of $m c r-1$ genes $[1,4]$. Investigation of archival strains dated the presence of mcr-1 back to at least the 1980 [5]. As with other resistance genes, minor allelic variants of $m c r-1$ have been detected [6]. More recently, additional transferable $\mathrm{mcr}$ genes ( $\mathrm{mcr}-2, \mathrm{mcr}-3, \mathrm{mcr}-4, \mathrm{mcr}-5, \mathrm{mcr}$ 6, mcr-7 and mcr-8) have been reported, for which the global epidemiology remains to be clarified [7-13].

In South America, $m c r-1$ genes have been reported from several countries in isolates from humans, animals 
Features of the study population, stratified by mcr-1-positive and -negative children, Chaco, Bolivia, September-October 2016

\begin{tabular}{|c|c|c|c|c|c|c|c|}
\hline Characteristics & $\begin{array}{l}\text { Total } \\
(\mathrm{n} / \mathrm{N})\end{array}$ & $\%$ & $\begin{array}{c}m c r-1 \text {-negative } \\
(\mathrm{n} / \mathrm{N})\end{array}$ & $\%$ & $\begin{array}{c}\text { mcr-1-positive } \\
(\mathrm{n} / \mathrm{N})\end{array}$ & $\%$ & P value \\
\hline \multicolumn{8}{|l|}{ Sex } \\
\hline Male & $158 / 337$ & 47 & $100 / 208$ & 48 & $58 / 129$ & 45 & \multirow{2}{*}{0.58} \\
\hline Female & $179 / 337$ & 53 & $108 / 208$ & 52 & $71 / 129$ & 55 & \\
\hline \multicolumn{8}{|l|}{ Age (years) } \\
\hline Mean $(95 \% \mathrm{Cl})$ & $9.3(9.1-9.4)$ & NA & $9.3(9.1-9.5)$ & NA & $9.2(9.0-9.5)$ & NA & \multirow{2}{*}{0.81} \\
\hline Median (IQR) & $9(8-10)$ & $\mathrm{NA}$ & $9(8-10)$ & NA & $9(8-10)$ & NA & \\
\hline Prior antibiotic use ${ }^{a}$ & $4 / 337$ & 1 & $3 / 208$ & 1 & $1 / 129$ & 1 & 0.58 \\
\hline
\end{tabular}

$\mathrm{Cl}$ : confidence interval; IQR: interquartile range; NA: not applicable. an the last 15 days.

and food [14-27]. Recently, the Pan American Health Organisation (PAHO) section of the World Health Organization (WHO) recommended to implement and strengthen surveillance and epidemiological investigation of plasmid-mediated transferable colistin resistance in its Member States [14]. In Bolivia, mcr-1 has thus far been reported in a Citrobacter braakii that was isolated from a ready-to-eat food sample [21], as well as in a few clinical isolates of $E$. coli referred from various departments to the National Institute of Health Laboratories (INLASA) (data not shown).

During the last two decades we carried out several surveillance studies in the Bolivian Chaco region, documenting a high prevalence of resistance to old and more recent antibiotics in commensal and pathogenic bacteria from humans [21,28-32].

In 2016, a new surveillance study was carried out in a population of healthy school children from several rural communities in this region to investigate the prevalence of intestinal parasites and the carriage of antibiotic-resistant bacteria. Here we report about an unexpected and high rate of faecal carriage of $\mathrm{mcr}$ 1-positive Enterobacterales in this population.

\section{Methods}

\section{Study population and setting}

The study population consisted of healthy school children living in eight rural communities of the Chaco region, in south-eastern Bolivia (between longitude $63^{\circ} 66$ and $63^{\circ} 18$ east and latitude $19^{\circ} 49$ and $21^{\circ} 88$ south, Figure 1). In these communities, the population lives in houses mostly constructed of mud and sticks, with packed earth floors and straw or corrugated metal roofs. There is no wired electricity and no sewage system. The main water sources are small ponds, in which animals also bathe and drink, and outdoor taps. The economy is mostly based on subsistence farming and local animal husbandry.

In each community, children were selected among those attending primary school, starting from the third year and possibly including the upper years, to achieve a number of ca 50 individuals per site whenever possible. This sample size corresponded to that recommended by WHO for cluster sampling in helminth control programmes in healthy school children [33].

Previous use of antibiotics during the last 15 days was investigated by a questionnaire administered to parents.

\section{Laboratory analyses}

Screening for $m c r-1$ - and $m c r$-2-positive strains in faecal samples

One faecal sample for each child was collected during a two-month period from September to October 2016; the samples were transferred to the Laboratories of Camiri or Villa Montes Hospitals within 6 hours and were plated onto MacConkey agar. After incubation at $35^{\circ} \mathrm{C}$ for 24 hours, the bacterial growth (representative of the total enterobacterial microbiota) was collected with a sterile swab in an Amies transport medium and was shipped to Italy. Each sample was then subcultured on MacConkey agar again, and the bacterial growth was resuspended in Brain Heart Infusion broth plus $20 \%(\mathrm{v} / \mathrm{v})$ glycerol and stored at $-70^{\circ} \mathrm{C}$ pending further analyses.

To screen for the presence of $m c r$-1- and $m c r$-2-positive strains, the preserved suspensions of total enterobacterial microbiota were thawed and $10 \mu \mathrm{l}$ were inoculated onto McConkey supplemented with colistin (2 $\mathrm{mg} / \mathrm{L}, \mathrm{MCC}$ medium). After incubation at $35^{\circ} \mathrm{C}$ for 24 hours, a loopful of the bacterial growth (taken either from confluent growth or from isolated colonies of 
Susceptibility of $m c r$ 1-positive Escherichia coli isolates to various antimicrobials, Chaco, Bolivia, September-October 2016 $(\mathrm{n}=171)$

\begin{tabular}{|l|c|c|c|c|c|c|c|c|c|c|c|c|c|c|c|c|c|c|c|c|c|c|c|}
\hline AMC & \multicolumn{2}{c|}{ PTZ } & \multicolumn{2}{c|}{ CAZ } & \multicolumn{2}{c|}{ CTX } & \multicolumn{2}{c|}{ FEP } & \multicolumn{2}{c|}{ MEM } & \multicolumn{2}{|c|}{ ERT } & \multicolumn{2}{c|}{ GEN } & \multicolumn{3}{c|}{ CIP } & \multicolumn{2}{|c|}{ TIG } & \multicolumn{2}{c|}{ COL } & \multicolumn{2}{c|}{ Total } \\
\hline $\mathrm{n}$ & $\%$ & $\mathrm{n}$ & $\%$ & $\mathrm{n}$ & $\%$ & $\mathrm{n}$ & $\%$ & $\mathrm{n}$ & $\%$ & $\mathrm{n}$ & $\%$ & $\mathrm{n}$ & $\%$ & $\mathrm{n}$ & $\%$ & $\mathrm{n}$ & $\%$ & $\mathrm{n}$ & $\%$ & $\mathrm{n}$ & $\%$ & $\mathrm{n}$ & $\%$ \\
\hline 72 & 42.1 & 171 & 100 & 130 & 76.0 & 128 & 74.9 & 130 & 76.0 & 171 & 100 & 171 & 100 & 138 & 80.7 & 62 & 36.3 & 171 & 100 & 168 & 1.7 & 171 & 100 \\
\hline
\end{tabular}

AMC: amoxicillin/clavulanate (clavulanate at fixed concentration of $4 \mathrm{mg} / \mathrm{L}$ ); CAZ: ceftazidime; CIP: ciprofloxacin; COL: colistin; CTX: cefotaxime; ERT: ertapenem; FEP: cefepime; GEN: gentamicin; MEM: meropenem; PTZ: piperacillin/tazobactam (tazobactam at fixed concentration of $4 \mathrm{mg} / \mathrm{L}$ ); TIG: tigecycline.

Numbers and percentages of susceptible isolates are given.

different morphologies) was resuspended in $300 \mu$ of normal saline, and half of the bacterial suspension was used to prepare a crude DNA extract by heating at $99^{\circ} \mathrm{C}$ for 15 minutes. The crude extracts were then screened for the presence of $m c r-1$ and $m c r-2$ genes by real-time (RT) PCR, as described previously [34]. In the case of a positive result, the remaining bacterial suspension was used to inoculate the MCC medium to obtain isolated colonies, and all isolated colonies of different morphology were then tested for the presence of $\mathrm{mcr}$ genes by RT-PCR. The $m c r$-positive isolates were identified using MALDI-TOF mass spectrometry (Vitek MS, bioMérieux, Marcy-l'Etoile, France).

When a sample yielded two or more mcr-1-positive isolates of the same species, clonal relatedness of the isolates was investigated by random amplification of polymorphic DNA (RAPD) profiling, as described previously [35]. The three $m c r$-positive isolates that were colistin susceptible were subjected to $\mathrm{mcr}$ gene amplification and sequencing using previously described primers and conditions [34].

Antimicrobial susceptibility testing

Antimicrobial susceptibility testing was carried out using reference broth microdilution [36]. Minimum inhibitory concentration (MIC) results were interpreted according to the European Committee on Antimicrobial Susceptibility Testing (EUCAST) clinical breakpoints [36].

Analysis of extended-spectrum $\beta$-lactamases

All isolates showing a ceftazidime and/or cefotaxime MIC>1 mg/L were screened for extended-spectrum $\beta$-lactamases (ESBL) production by a combination disk test using ceftazidime and cefotaxime as substrates and clavulanic acid as an inhibitor [37]. ESBLpositive isolates by phenotypic testing were subjected to RT-PCR for the detection of bla ${ }_{\text {CTX-M }}$ ESBL genes, as described previously [38].

Whole genome sequencing

A subset of $18 \mathrm{mcr}$-1-positive isolates were subjected to whole genome sequencing (WGS) analysis. This subset comprised two $E$. coli isolates per community: from randomly selected individuals co-colonised by two different mcr-1-positive $E$. coli or from two randomly selected individuals if co-colonisations were not detected and the two non-E. coliisolates bore $\mathrm{mcr}$ 1. For the latter, species identification was carried out by the analysis of housekeeping genes $[39,40]$. Bacterial genomic DNA of these 18 selected mcr-positive isolates, extracted using the phenol-chloroform method [41], was subjected to WGS with a MiSeq platform (Illumina, Inc., San Diego, California, United States (US)) using a 2×300 paired-end approach. Raw reads were assembled using SPAdes 3.5 [42]. An average of 120 contigs per strain was obtained, with an average $\mathrm{N}_{50}$ of $163 \mathrm{~Kb}$. Draft genomes have been deposited in the National Center for Biotechnology Information (NCBI) WGS database under the BioProject PRJNA427943 (accession numbers: PQTOo0000000; PQTNo0000000; PQTM00000000; PQTLO०000000; PQTKo००००००o; PQTJ00000000; PQTI00000000; PQTH00000000; PQTG00000000; PQTFO०000000; PQTE PQTB०0000000; PQTA00000000; PQSZ00000000; PQSYo0000000; PQSXoo000000). Resistance genes and plasmid content were investigated using the ResFinder and PlasmidFinder tools available at the Center for Genomic Epidemiology at https://cge.cbs. $\mathrm{dtu} . \mathrm{dk} /$ services/ResFinder/. Clonal relatedness was investigated by in silico determination of the multilocus sequence typing (MLST) profile obtained by the MLST 1.8 software (available at https://cge.cbs.dtu. $\mathrm{dk} /$ services/MLST/) using the assembled WGS as input data.

\section{Statistical analysis}

Statistical analysis of the data was performed with STATA 11.0 (StataCorp, College Statio, Texas, US). Frequencies and percentages with 95\% confidence intervals $(\mathrm{Cl})$ for categorical variables, medians and interquartile ranges (IQR) for continuous variables were calculated. Mann-Whitney test was used to compare median age. Chi-squared test was used to investigate the association of mcr-1 carriage with sex and prior antibiotic use. Results were considered significant when the $p$ value was $\leq 0.05$.

\section{Ethical statement}

Written informed consent was always obtained from parents or legal guardians. The investigation was planned and carried out within a collaboration 
TABLE 3

Features of $m c r$-1-positive isolates subjected to whole genome sequencing analysis, Chaco, Bolivia, September-October 2016 $(\mathrm{n}=18)$

\begin{tabular}{|c|c|c|c|c|c|c|c|c|}
\hline Community & $\begin{array}{l}\text { Isolate } \\
\text { code }\end{array}$ & $\begin{array}{l}\text { Subject } \\
\text { code }\end{array}$ & Species & $\begin{array}{l}\text { Additional } \\
\text { resistance } \\
\text { trait(s) }\end{array}$ & Acquired resistance genes ${ }^{b}$ & $S T^{c}$ & $\begin{array}{l}m c r \text { variant and } \\
\text { genetic contextd }\end{array}$ & $\begin{array}{l}\text { mcr contig } \\
\text { size (bp) }\end{array}$ \\
\hline \multirow[b]{2}{*}{ Palmarito } & $12 \mathrm{~A}$ & 1 & Escherichia coli & $\begin{array}{l}A M C ; G E N ; \\
\quad C I P\end{array}$ & $\begin{array}{l}\text { blaTEM-1B; aac (3)-IV; aph (4)- } \\
\text { Ia; fosA3; floR; qnrB19; tet }(A)\end{array}$ & 48 & $m c r-1-p a p(\operatorname{Inc|} 2)$ & 61,600 \\
\hline & $12 \mathrm{~B}$ & 1 & E. coli & GEN; CIP & $\begin{array}{c}\text { blaTEM-1B; aac (3)-IV; } \\
\text { aph(3')-la; aph (4)-la; strA; } \\
\text { strB; catA1; floR; oqxA; oqxB; } \\
\text { sul2; tet(A) }\end{array}$ & 744 & $m c r-1-p a p(\operatorname{Incl} 2)$ & 60,992 \\
\hline \multirow[b]{2}{*}{ Ivamirapinta } & $155 \mathrm{~A}$ & 2 & E. coli & $\mathrm{FS}^{\mathrm{e}}$ & ND & 10 & $m c r-1-p a p(\operatorname{Incl} 2)$ & 60,547 \\
\hline & $155 B$ & 2 & E. coli & $A M C ; C I P$ & $\begin{array}{c}\text { blaTEM-1A; aadA1; aadA2; strA; } \\
\text { strB; cmlA1; floR; qnrB19; sul2; } \\
\text { sul3; tet }(A) ; \text { dfrA8 }\end{array}$ & 206 & $m c r-1$-unk ${ }^{f}$ & 2,943 \\
\hline \multirow{3}{*}{ Tetapiau/Kurupaity } & $86 \mathrm{~A}$ & 3 & E. coli & $A M C ; C I P$ & $\begin{array}{l}\text { blaTEM-1B; strA; strB; floR; } \\
\text { qnrB19; sul2; tet }(A) ; d f r A 1\end{array}$ & 2,705 & $m c r-1-$ unk $^{f}$ & 2,942 \\
\hline & $86 \mathrm{~B}$ & 3 & E. coli & $A M C ; C I P$ & $\begin{array}{l}\text { blaTEM-1B; aadA1; aadA2; strA; } \\
\text { str } B ; \operatorname{cm} l_{A 1} ; \text { floR; sul1; sul } 2 \\
\text { sul } 3 ; \operatorname{tet}(A) ; \operatorname{tet}(B) ; d f r A 1 ; d f r A 12\end{array}$ & 2,936 & $\begin{array}{l}\text { mcr-1.5-pap- } \\
\text { ISApl1(IncHI1) }\end{array}$ & 13,7897 \\
\hline & $67 \mathrm{~A}$ & 4 & $\begin{array}{l}\text { Citrobacter } \\
\text { europaeus }\end{array}$ & $A M C$ & qnrB19; qnrB28 & NA & $m c r-1-p a p(|n c| 2)$ & 60,321 \\
\hline \multirow{2}{*}{$\begin{array}{l}\text { San Antonio del } \\
\text { Parapetí }\end{array}$} & $173 \mathrm{~A}$ & 5 & E. coli & $\begin{array}{l}A M C ; C I P ; \\
G E N ; C A Z ; \\
C T X ; F E P ; \\
\text { (ESBL) }\end{array}$ & $\begin{array}{c}\text { blaCTX-M-55; aadA1; aadA2; } \\
\text { aadA5; rmtB; fosA3; cmlA1; floR; } \\
\text { qnrB19; sul3; tet }(A) ; \text { dfrA17 }\end{array}$ & 1,286 & $m c r-1-$ unk $^{f}$ & 6,134 \\
\hline & 173B & 5 & E. coli & $\begin{array}{l}\text { AMC; CIP; } \\
\text { GEN; CAZ; } \\
\text { CTX; FEP; } \\
\text { (ESBL) }\end{array}$ & $\begin{array}{l}\text { blaCTX-M-55; blaTEM-1B; } \\
\text { aadA1; } \operatorname{aadA2} ; \operatorname{rmtB} ; \operatorname{cmlA} 1 ; \\
\text { floR; qnrB19; sul3; tet(A) }\end{array}$ & 1,286 & $m c r-1-$ unk $^{f}$ & 2,863 \\
\hline \multirow{2}{*}{ Tarairí } & $224 \mathrm{~A}$ & 6 & E. coli & AMC & $\begin{array}{c}\text { aadA1; aadA2; strA; strB; } \\
\text { cmlA1; floR; qnrB19; sul2; sul3; } \\
\text { tet(A); tet(B); dfrA14 }\end{array}$ & 2,705 & $m c r-1-p a p(\operatorname{Inc|} 2)$ & 59,561 \\
\hline & $224 B$ & 6 & E. coli & AMC; CIP & $\begin{array}{l}\text { blaTEM-1B; } \operatorname{aad} A 1 ; \operatorname{aad} A 2 ; \operatorname{str} A ; \\
\text { strB; } \operatorname{cml} 1 ; \text { floR; } Q \text { nrB19; sul2; } \\
\text { sul3; tet(A); tet(B); dfrA14 }\end{array}$ & 7,570 & $\begin{array}{c}\text { DISApl1- } \\
\text { mcr-1-pap- } \\
\text { ISApl1 }(\operatorname{IncHI})\end{array}$ & 52,737 \\
\hline \multirow{3}{*}{ Palmar Chico } & $306 \mathrm{~A}$ & 7 & E. coli & AMC & $\begin{array}{l}\text { blaTEM-1B; aadA5; strA; strB; } \\
\text { sul1; sul2; dfrA17 }\end{array}$ & 69 & $m c r-1-p a p(\operatorname{Inc|} 2)$ & 63,921 \\
\hline & $306 \mathrm{~B}$ & 7 & E. coli & AMC; CIP & $\begin{array}{l}\text { blaTEM-1B; blaOXA-1; aadA1; } \\
\text { sul1; tet }(\mathrm{X})\end{array}$ & 10 & $m c r-1-p a p(\operatorname{Incl} 2)$ & 64,425 \\
\hline & $301 \mathrm{~B}$ & 8 & $\begin{array}{l}\text { Enterobacter } \\
\text { hormaechei }\end{array}$ & $\mathrm{FS}^{\mathrm{e}}$ & ND & - & $m c r-1-p a p(\operatorname{Inc} \mid 2)$ & 63,943 \\
\hline \multirow[t]{2}{*}{ Capirendita } & $286 \mathrm{~A}$ & 9 & E. coli & AMC & $\begin{array}{c}\text { blaTEM-1B; aadA1; floR; sul3; } \\
\text { tet(A); tet(C); dfrA1 }\end{array}$ & 117 & $m c r-1-p a p(\operatorname{Inc|} 2)$ & 59,748 \\
\hline & $295^{B}$ & 10 & E. coli & $\mathrm{FS}^{\mathrm{e}}$ & ND & 711 & $m c r-1-p a p(\operatorname{Incl} 2)$ & 56,317 \\
\hline \multirow[b]{2}{*}{ Chimeo } & $274 \mathrm{~A}$ & 11 & E. coli & $\begin{array}{l}\text { AMC; GEN; } \\
\text { CIP }\end{array}$ & $\begin{array}{c}\text { blaTEM-1B; aac (3)-IV; aadA1; } \\
\text { aadA2; aph(3)-la; cmlA1; floR; } \\
\text { qnrB19; sul } 2 ; \text { sul } 3 ; \operatorname{tet}(A) ; \\
\text { tet(M); dfrA12 }\end{array}$ & 7,571 & $m c r-1-u_{n} k^{f}$ & 2,943 \\
\hline & $274 B$ & 11 & E. coli & $\begin{array}{l}\text { AMC; CAZ; } \\
\text { CTX; FEP } \\
\text { (ESBL) }\end{array}$ & $\begin{array}{c}\text { blaCTX-M-55; blaTEM-1B; } \\
\text { blaOXA-10; aac(6')lb-cr; aacA4; } \\
\text { aadA1; strA; strB; fosA3; cmlA1; } \\
\text { floR; qnrB19; qnrVC4; sul2; } \\
\text { tet(A); dfrA14 }\end{array}$ & 3,056 & $m c r-1-p a p(\operatorname{Inc|} 2)$ & 60,652 \\
\hline
\end{tabular}

AMC: amoxicillin/clavulanate (clavulanate at fixed concentration of $4 \mathrm{mg} / \mathrm{L}$ ); CAZ: ceftazidime; CIP: ciprofloxacin; COL: colistin; CTX:

cefotaxime; ESBL: extended-spectrum $\beta$-lactamase; FEP: cefepime; FS: fully susceptible; GEN: gentamicin; NA: not applicable; ND: none detected; ST: sequence type; unk: unknown.

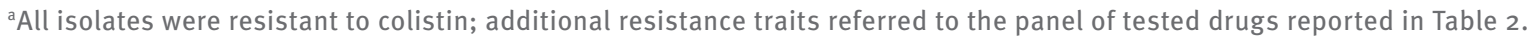

${ }^{b}$ Acquired resistance genes as determined by analysis with the ResFinder software.

'Sequence-types were assigned using the Warwick scheme (http://enterobase.warwick.ac.uk/species/index/ecoli).

dIf the gene was linked with a known plasmid backbone, the plasmid replicon type is reported in brackets.

eThe isolate was susceptible to all tested agents except colistin.

${ }^{f}$ In these cases it was not possible to reveal the nature of flanking regions due to the presence of repeated sequences flanking the gene.

For each isolate, the epidemiological data, additional resistance profile, acquired resistance genes content, sequence type and mcr genetic context are reported. 
agreement between the Ministry of Health of the Plurinational State of Bolivia and the University of Florence, Italy, and with the support of the Guaraní political organisation (Asamblea del Pueblo Guaraní). Ethical approval for the study was obtained from the above-mentioned institutions (see Acknowledgements section).

\section{Results}

Faecal specimens were obtained from 337 healthy school children in eight rural communities of the Bolivian Chaco region (Figure 1). Children (179 females; 53\%;) were aged 7 to 11 years (mean: 9.2 years). Previous antibiotic exposure was only reported for four children.

\section{mcr-1 carriage}

All 337 samples of enterobacterial microbiota yielded some growth (from scanty to vigorous) on the MCC medium, and 129 (38.3\%) yielded a positive result for $m c r-1$. Positive samples were detected in children from each village, although at variable rates (range: 19.1-80.5\%; Figure 1). No $\mathrm{mcr}-2$ genes were detected. One or more $\mathrm{mcr}$-1-positive isolates were recovered from each of the 129 samples, yielding a total of 173 positive isolates, including $171 \mathrm{E}$. coli, one Citrobacter spp. and one Enterobacter spp.. Multiple mcr-1-positive isolates from the same sample consisted of either two or three $E$. coli isolates of different colonial morphology and RAPD profile (in 32 and 5 samples, respectively), or in an $E$. coli plus an Enterobacter spp. (in one sample). No differences were found in the demographic characteristics, sex or age, of children carrying $\mathrm{mcr}$-1-positive Enterobacterales or children without $\mathrm{mcr}_{-1}$ carriage (Table 1), nor were there any differences in the living conditions of the communities with different proportions of carriers (data not shown).

\section{Antimicrobial susceptibility of $m c r-1$-positive isolates}

Colistin susceptibility testing showed that the majority $(n=170 ; 98.3 \%)$ of the $m c r-1$-positive isolates were resistant to colistin (MIC range: $4^{->8} \mathrm{mg} / \mathrm{L}$ ), while only three $E$. coli (from different villages) were colistin-susceptible (all with an MIC of $2 \mathrm{mg} / \mathrm{L}$ ) (Table 2). Sequencing of $\mathrm{mcr}$ amplicons from the latter isolates showed identity with $m c r-1$, suggesting that the colistin susceptible phenotype was not due to mutations inactivating the gene. Variable resistance rates to other antimicrobial agents were observed, including fluoroquinolones, expanded-spectrum cephalosporins, $\beta$-lactamase plus inhibitor combinations and gentamicin. All isolates were susceptible to carbapenems and tigecycline (Table 2).

\section{Diversity of the $m c r-1$-positive isolates}

WGS analysis of the subset of $18 \mathrm{mcr}$-1-positive isolates confirmed the identification of the two non- $E$. coli isolates as Citrobacter europaeus and Enterobacter hormaechei, respectively (Table 3), two species in which $\mathrm{mcr}-1$ was not previously reported.
In silico MLST analysis of the $16 E$. coli isolates revealed a considerable diversity, with only a few isolates from different villages belonging to the same sequence type (ST). All but one of the couples isolated from the same individual belonged to different STs (Table 3).

Analysis of the acquired resistance genes showed a remarkable diversity and a variety of patterns (Table $3)$. The number of known acquired resistance genes varied from o to 16 (median: 9). Overall, the resistance gene content was consistent with the susceptibility profile. The three ESBL-positive $E$. coli isolates carried the bla $a_{\text {CTX-M-55 }}$ variant previously reported in Bolivia [30]. Analysis of the mcr-1 carrying contigs revealed that in 13 isolates the $m c r-1$ gene was linked to backbone regions typical of Incl2 or IncHl1 plasmids, suggesting a plasmid location, with some plasmid diversity. In the remaining five isolates, it was not possible to determine the nature of flanking regions due to the presence of repeated sequences flanking the gene (Table 3 ).

\section{Discussion}

Our study revealed a very high prevalence of carriage of $\mathrm{mcr}$-1-positive strains among healthy children living in rural communities of the Bolivian Chaco. Carriage of $\mathrm{mcr}$-1-positive strains in healthy humans has been investigated in a limited number of studies, mostly from Asian countries [41-53]. The prevalence rates detected in such studies have usually been low ( $<5 \%)$, except in a group of chicken farmers from Vietnam, where a $34.7 \%$ carriage rate of $m c r$-1-positive $E$. coli was detected and attributed to professional exposure to $m c r-1$-positive animals [45]. Therefore, to our best knowledge, we present the highest rate of $\mathrm{mcr}-1$ carriage thus far reported in healthy humans.

In our study, professional exposure could be excluded as a reason for the high prevalence of $\mathrm{mcr}_{-1}$ carriage, as well as human use of colistin. Overall, only four children had prior exposure to antibiotics and the use of colistin in Bolivia is occasional and limited to infections by some multi-drug resistant pathogens in large urban hospitals (data not shown). However, colistin is available with no restrictions for veterinary use and in animal breeding [54], and we hypothesise that this could have played a major role in the selection of colistin-resistant strains in the animal population and the environment. Moreover, the introduction of $\mathrm{mcr}$-positive strains via imported food and/or food-producing animals from countries where their prevalence was found to be high (e.g. Brazil) $[15,22]$ could also represent a source of such strains. Poor sanitation and close contact with animals, which characterise the studied setting, may lead to a high level of environmental contamination and facilitate cross-transmission of colistinresistant strains and colistin resistance genes between different environments, resulting in a high prevalence in humans who are not directly exposed to the drug.

In our case, only a minority of the mcr-positive isolates showed resistance to other antimicrobials, and 
no carbapenem resistance was detected, leaving a number of therapeutic options in case of infection. However, the potential risk of spread of the $\mathrm{mcr}-1$ gene to extensively resistant isolates through transferable plasmids mechanisms should not be underestimated.

Genomic analysis of a subset of the $m c r$-1-positive $E$. coli isolates, representative of different communities and of different isolates from the same child, revealed a remarkable heterogeneity in terms of clonal lineages and genetic supports. Therefore, the observed epidemiological scenario could not be ascribed to the expansion of a single mcr-1-positive clone, nor even to the spread of a single plasmid. The diversity of the genetic background of the mcr-1 genes underlined the ability of this gene to transfer itself among different clones (and even different species) and plasmids. Interestingly, we detected for the second time in South America the mcr-1.5 variant, previously described in an E. colistrain from Argentina [23].

Our study has some limitations. First, the presence of animal or environmental reservoirs of $m c r$-positive isolates and the direct transmission between humans and animals/environment could not be demonstrated, since we did not collect any samples from animals or the environment. Second, apart from $\mathrm{mcr}$-2, we did not search for other recently described $m c r$-variants that could be responsible for resistance observed in other isolates. Third, the study was designed as a cross-sectional survey, in which one sample from each individual was collected. It would be interesting to investigate the prevalence of $m c r-1$ carriage in adults and the duration of carriage over time to understand if and how much humans could represent a major reservoir in this setting. It would also be interesting to further characterise, in more detail, the plasmid supports of the $\mathrm{mcr}-1$ and other resistant determinants. Investigations on these aspects are underway.

In conclusion, our findings prompt the need to rapidly monitor the extent of human and animal carriage rates and environmental contamination by $\mathrm{mor}$ genes with a one-health approach, and to introduce policies banning the non-therapeutic use of colistin. This was also recently highlighted by the $\mathrm{PAHO} / \mathrm{WHO}$, which encouraged the implementation of animal-human surveillance, as well as actions to prevent and control the spread of mcr-positive microorganisms, such as the monitoring of colistin use in human food production [14]. In Europe, knowledge of mcrcarriage among healthy individuals is still limited $[47,53]$. While available data suggest a very low occurrence, it will be interesting to study human and animal carriage rates and environmental contamination in different countries and settings.

\section{Acknowledgements}

The Bolivian Ministry of Health and the Regional Health Departments approved the study design, including its ethical aspects; the Guaraní political organization (Asamblea del Pueblo Guaraní) supported the field work and conducted the interviews.

\section{Conflict of interest}

None declared.

\section{Authors' contributions}

TG and SS analysed the data and drafted the manuscript; AA, VDP, CN did the molecular analysis and genome sequencing; TM, AM and LP produced phenotypic data and handled the samples; MS, MM, FC, JM, PC, DBV, ED, SM and RR collected the samples and participated in the coordination of the survey; $A B$ and GMR coordinated the survey and edited the manuscript.

\section{References}

1. Poirel L, Jayol A, Nordmann P. Polymyxins: antibacterial activity, susceptibility testing, and resistance mechanisms encoded by plasmids or chromosomes. Clin Microbiol Rev. 2017;30(2):557-96. https://doi.org/10.1128/CMR.00064-16 PMID: 28275006

2. Liu YY, Wang Y, Walsh TR, Yi LX, Zhang R, Spencer J, et al. Emergence of plasmid-mediated colistin resistance mechanism MCR-1 in animals and human beings in China: a microbiological and molecular biological study. Lancet Infect Dis. 2016;16(2):161-8. https://doi.org/10.1016/S14733099(15)00424-7 PMID: 26603172

3. Giamarellou H. Epidemiology of infections caused by polymyxin-resistant pathogens. Int J Antimicrob Agents. 2016;48(6):614-21. https://doi.org/10.1016/j. ijantimicag.2016.09.025 PMID: 27865627

4. Schwarz S, Johnson AP. Transferable resistance to colistin: a new but old threat. A Antimicrob Chemother, 2016;71(8):206670. https://doi.org/10.1093/jac/dkw274 PMID: 27342545

5. Shen Z, Wang Y, Shen Y, Shen J, Wu C. Early emergence of mcr-1 in Escherichia coli from food-producing animals. Lancet Infect Dis. 2016;16(3):293. https://doi.org/10.1016/S14733099(16)00061-X PMID: 26973308

6. Rebelo AR, Bortolaia V, Kjeldgaard IS, Pedersen SK Leekitcharoenphon P, Hansen IM, et al. Multiplex PCR for detection of plasmid-mediated colistin resistance determinants, mcr-1, mcr-2, mcr-3, mcr- 4 and mcr- 5 for surveillance purposes. Euro Surveill. 2018;23(6):17-00672. https://doi.org/10.2807/1560-7917.ES.2018.23.6.17-00672 PMID: 29439754

7. Xavier BB, Lammens C, Ruhal R, Kumar-Singh S, Butaye P, Goossens $\mathrm{H}$, et al. Identification of a novel plasmid-mediated colistin-resistance gene, mcr-2, in Escherichia coli, Belgium, June 2016. Euro Surveill. 2016;21(27):30280. https://doi. org/10.2807/1560-7917.ES.2016.21.27.30280 PMID: 27416987

8. Yin W, Li H, Shen Y, Liu Z, Wang S, Shen Z, et al. Novel plasmid-mediated colistin resistance gene mcr-3 in Escherichia coli. MBio. 2017;8(4):e01166-17. https://doi.org/10.1128/ mBio.01166-17 PMID: 28811346

9. Carattoli A, Villa L, Feudi C, Curcio L, Orsini S, Luppi A, et al. Novel plasmid-mediated colistin resistance mcr-4 gene in Salmonella and Escherichia coli, Italy 2013, Spain and Belgium, 2015 to 2016. Euro Surveill. 2017;22(31):30589. https://doi.org/10.2807/1560-7917.ES.2017.22.31.30589 PMID: 28797329

10. Borowiak M, Fischer J, Hammerl JA, Hendriksen RS, Szabo I, Malorny B. Identification of a novel transposon-associated phosphoethanolamine transferase gene, $\mathrm{mcr}-5$, conferring colistin resistance in d-tartrate fermenting Salmonella enterica subsp. enterica serovar Paratyphi B. J Antimicrob Chemother. 2017;72(12):3317-24. https://doi.org/10.1093/jac/dkx327 PMID: 28962028

11. AbuOun M, Stubberfield EJ, Duggett NA, Kirchner M, Dormer L, Nunez-Garcia J, et al. mcr-1 and mcr-2 variant genes identified in Moraxella species isolated from pigs in Great Britain from 2014 to 2015. J Antimicrob Chemother. 2017;72(10):2745-9. https://doi.org/10.1093/jac/dkx286 PMID: 29091227

12. Yang YQ, Li YX, Lei CW, Zhang AY, Wang HN. Novel plasmidmediated colistin resistance gene mcr-7.1 in Klebsiella 
pneumoniae. J Antimicrob Chemother. 2018;73(7):1791-5. https://doi.org/10.1093/jac/dky111 PMID: 29912417

13. Wang X, Wang Y, Zhou Y, Li J, Yin W, Wang S, et al. Emergence of a novel mobile colistin resistance gene, $\mathrm{mcr}-8$, in NDMproducing Klebsiella pneumoniae. Emerg Microbes Infect. 2018;7(1):122. https://doi.org/10.1038/s41426-018-0124-z PMID: 29970891

14. Pan American Health Organization (PAHO)/World Health Organization (WHO). Epidemiological Alert: Enterobacteriaceae with plasmid-mediated transferable colistin resistance, public health implications in the Americas, 10 June 2016. Washington, D.C./Geneva: PAHO/WHO; 2016. Available from: http://www. paho.org/hq/index.php?option=com_docman\&task=doc_view \&ltemid=270\&gid $=35007$ \&lang $=e n$

15. Fernandes MR, Moura Q, Sartori L, Silva KC, Cunha MP, Esposito F, et al. Silent dissemination of colistin-resistant Escherichia coli in South America could contribute to the global spread of the mcr-1 gene. Euro Surveill. 2016;21(17):30214. https://doi.org/10.2807/1560-7917.ES.2016.21.17.30214 PMID: 27168587

16. Rapoport M, Faccone D, Pasteran F, Ceriana P, Albornoz E, Petroni A, et al. MCR Group. First description of mcr-1-mediated colistin resistance in human infections caused by Escherichia coli in Latin America. Antimicrob Agents Chemother. 2016;6o(7):4412-3. https://doi.org/10.1128/AAC.00573-16 PMID: 27090181

17. Delgado-Blas JF, Ovejero CM, Abadia-Patiño L, Gonzalez-Zorn B. Coexistence of mcr-1 and blaNDM-1 in Escherichia coli from Venezuela. Antimicrob Agents Chemother. 2016;60(10):6356-8. https://doi.org/10.1128/AAC.01319-16 PMID: 27431212

18. Dalmolin TV, Martins AF, Zavascki AP, de Lima-Morales D, Barth AL. Acquisition of the mcr-1 gene by a high-risk clone of KPC-2-producing Klebsiella pneumoniae ST437/CC258, Brazil. Diagn Microbiol Infect Dis. 2018;90(2):132-3. https://doi. org/10.1016/j.diagmicrobio.2017.09.016 PMID: 29169659

19. Saavedra SY, Diaz L, Wiesner M, Correa A, Arévalo SA, Reyes J, et al. Genomic and Molecular characterization of clinical isolates of Enterobacteriaceae harboring mcr-1 in Colombia, 2002 to 2016. Antimicrob Agents Chemother. 2017;61(12):eoo8441-17. https://doi.org/10.1128/AAC.00841-17 PMID: 28893788

20. Ortega-Paredes D, Barba P, Zurita J. Colistin-resistant Escherichia coli clinical isolate harbouring the mcr-1 gene in Ecuador. Epidemiol Infect. 2016;144(14):2967-70. https://doi. org/10.1017/So950268816001369 PMID: 27586373

21. Sennati S, Di Pilato V, Riccobono E, Di Maggio T, Villagran AL, Pallecchi $L$, et al. Citrobacter braakii carrying plasmid-borne mcr-1 colistin resistance gene from ready-to-eat food from a market in the Chaco region of Bolivia. I Antimicrob Chemother. 2017;72(7):2127-9. https://doi.org/10.1093/jac/dkx078 PMID: 28333311

22. Monte DF, Mem A, Fernandes MR, Cerdeira L, Esposito F, Galvão JA, et al. Chicken meat as a reservoir of colistinresistant Escherichia coli strains carrying mcr-1 genes in South America. Antimicrob Agents Chemother. 2017;61(5):e02718-16. https://doi.org/10.1128/AAC.02718-16 PMID: 28193665

23. Tijet N, Faccone D, Rapoport M, Seah C, Pasterán F, Ceriana $P$, et al. Molecular characteristics of mcr-1-carrying plasmids and new $\mathrm{mcr}-1$ variant recovered from polyclonal clinical Escherichia coli from Argentina and Canada. PLoS One. 2017;12(7):e0180347. https://doi.org/10.1371/journal. pone.0180347 PMID: 28678874

24. Fernandes MR, Sellera FP, Esposito F, Sabino CP, Cerdeira L, Lincopan N. Colistin-resistant mcr-1-positive Escherichia coli on public beaches, an infectious threat emerging in recreational waters. Antimicrob Agents Chemother. 2017;61(7):e00234-17. https://doi.org/10.1128/AAC.00234-17 PMID: 28416556

25. Aires CAM, da Conceição-Neto OC, Tavares E Oliveira TR, Dias CF, Montezzi LF, Picão RC, et al. Emergence of the plasmidmediated mcr-1 gene in clinical KPC-2-producing Klebsiella pneumoniae Sequence Type 392 in Brazil. Antimicrob Agents Chemother. 2017;61(7):e00317-17. https://doi.org/10.1128/ AAC.00317-17 PMID: 28438940

26. Sellera FP, Fernandes MR, Sartori L, Carvalho MPN, Esposito F, Nascimento CL, et al. Escherichia coli carrying Inc $X_{4}$ plasmidmediated mcr-1 and blaCTX-M genes in infected migratory Magellanic penguins (Spheniscus magellanicus). J Antimicrob Chemother. 2017;72(4):1255-6. PMID: 28031274

27. Rossi F, Girardello R, Morais C, Cury AP, Martins LF, da Silva AM, et al. Plasmid-mediated mcr-1 in carbapenemsusceptible Escherichia coli ST15 6 causing a blood infection: an unnoticeable spread of colistin resistance in Brazil? Clinics (Sao Paulo). 2017;72(10):642-4. https://doi.org/10.6061/ clinics/2017(10)09 PMID: 29160428

28. Bartoloni A, Cutts F, Leoni S, Austin CC, Mantella A, Guglielmetti P, et al. Patterns of antimicrobial use and antimicrobial resistance among healthy children in Bolivia. Trop Med Int Health. 1998;3(2):116-23. https://doi. org/10.1046/j.1365-3156.1998.00201.x PMID: 9537273

29. Bartoloni A, Pallecchi L, Riccobono E, Mantella A, Magnelli $\mathrm{D}$, Di Maggio T, et al. Relentless increase of resistance to fluoroquinolones and expanded-spectrum cephalosporins in Escherichia coli: 20 years of surveillance in resourcelimited settings from Latin America. Clin Microbiol Infect. 2013;19(4):356-61. https://doi.org/10.1111/j.14690691.2012.03807.x PMID: 22414066

30. Bartoloni A, Sennati S, Di Maggio T, Mantella A, Riccobono E, Strohmeyer M, et al. Antimicrobial susceptibility and emerging resistance determinants (blaCTX- $M, r m t B$, fos $\mathrm{A}_{3}$ ) in clinical isolates from urinary tract infections in the Bolivian Chaco. Int J Infect Dis. 2016;43:1-6. https://doi.org/10.1016/j. ijid.2015.12.008 PMID: 26686940

31. Bartoloni A, Riccobono E, Magnelli D, Villagran AL, Di Maggio T, Mantella A, et al. Methicillin-resistant Staphylococcus aureus in hospitalized patients from the Bolivian Chaco. Int J Infect Dis. 2015;30:156-6o. https://doi.org/10.1016/j. ijid.2014.12.006 PMID: 25486009

32. Pallecchi L, Malossi M, Mantella A, Gotuzzo E, Trigoso C, Bartoloni A, et al. Detection of CTX-M-type betalactamase genes in fecal Escherichia coli isolates from healthy children in Bolivia and Peru. Antimicrob Agents Chemother. 2004;48(12):4556-61. https://doi.org/10.1128/ AAC.48.12.4556-4561.2004 PMID: 15561825

33. World Health Organization (WHO)/Department of control of neglected tropical diseases. Helminth control in schoolaged children, a guide for managers of control programs. Geneva: WHO; 2012. Available from:http://www.who.int/ neglected_diseases/resources/9789241548267/en/

34. Coppi M, Cannatelli A, Antonelli A, Baccani I, Di Pilato V, Sennati S, et al. A simple phenotypic method for screening of MCR-1-mediated colistin resistance. Clin Microbiol Infect. 2018;24(2):S1198-743X(17)30457-3.

35. Pacheco AB, Guth BE, Soares KC, Nishimura L, de Almeida DF, Ferreira LC. Random amplification of polymorphic DNA reveals serotype-specific clonal clusters among enterotoxigenic Escherichia coli strains isolated from humans. J Clin Microbiol. 1997;35(6):1521-5. PMID: 9163473

36. European Committee on Antimicrobial Susceptibility Testing (EUCAST). Breakpoint tables for interpretation of MICs and zone diameters. Version 8.0. Växjö: EUCAST; 1 Jan 2018. Available from:http://www.eucast.org/fileadmin/src/media/ PDFs/EUCAST_files/Breakpoint_tables/v_8.o_Breakpoint_ Tables.pdf

37. European Committee on Antimicrobial Susceptibility Testing (EUCAST). EUCAST guideline for the detection of resistance mechanisms and specific resistances of clinical and/or epidemiological importance. Version 2.0. Växjö: EUCAST; July 2016. Available from:http://www.eucast.org/fileadmin/src/ media/PDFs/EUCAST_files/Resistance_mechanisms/EUCAST detection_of resistance_mechanisms_170711.pdf

38. Giani T, Antonelli A, Caltagirone M, Mauri C, Nicchi J, Arena F, et al. Evolving beta-lactamase epidemiology in Enterobacteriaceae from Italian nationwide surveillance, October 2013: KPC-carbapenemase spreading among outpatients. Euro Surveill. 2017;22(31):30583. https://doi. org/10.2807/1560-7917.ES.2017.22.31.30583 PMID: 28797330

39. Ribeiro TG, Novais Â, Branquinho R, Machado E, Peixe L. Phylogeny and comparative genomics unveil independent diversification trajectories of qnrB and genetic platforms within particular Citrobacter species. Antimicrob Agents Chemother. 2015;59(10):5951-8. https://doi.org/10.1128/ AAC.00027-15 PMID: 26169406

40. Chavda KD, Chen L, Fouts DE, Sutton G, Brinkac L, Jenkins SG, et al. Comprehensive genome analysis of carbapenemaseproducing Enterobacter spp.: new insights into phylogeny, population structure, and resistance mechanisms. MBio. 2016;7(6):e02093-16. https://doi.org/10.1128/mBio.02093-16 PMID: 27965456

41. Sambrook J, Fritsch EF, Maniatis T. Molecular cloning: a laboratory manual. Cold Spring Harbor, NY: Cold Spring Harbor Press; 1989.

42. Bankevich A, Nurk S, Antipov D, Gurevich AA, Dvorkin M, Kulikov AS, et al. SPAdes: a new genome assembly algorithm and its applications to single-cell sequencing. J Comput Biol. 2012;19(5):455-77. https://doi.org/10.1089/cmb.2012.0021 PMID: 22506599

43. Bi Z, Berglund B, Sun Q, Nilsson M, Chen B, Tärnberg M, et al. Prevalence of the mcr-1 colistin resistance gene in extendedspectrum $\beta$-lactamase-producing Escherichia coli from human faecal samples collected in 2012 in rural villages in Shandong Province, China. Int J Antimicrob Agents. 2017;49(4):4937. https://doi.org/10.1016/j.ijantimicag.2016.12.018 PMID: 28263896 
44. Purohit MR, Chandran S, Shah H, Diwan V, Tamhankar AJ, Stålsby Lundborg C. Antibiotic resistance in an Indian rural community: a 'One-Health' observational study on commensal coliform from humans, animals, and water. Int J Environ Res Public Health. 2017;14(4):386-13. https://doi.org/10.3390/ ijerph14040386 PMID: 28383517

45. Trung NV, Matamoros S, Carrique-Mas JJ, Nghia NH, Nhung NT, Chieu TTB, et al. Zoonotic transmission of mcr-1 colistin resistance gene from small-scale poultry farms, Vietnam. Emerg Infect Dis. 2017;23(3):529-32. https://doi.org/10.3201/ eid2303.161553 PMID: 28221105

46. Zhong LL, Zhang YF, Doi Y, Huang X, Zhang XF, Zeng KJ, et al. Co-production of MCR-1 and NDM-1 by colistin-resistant Escherichia coli isolated from a healthy individual. Antimicrob Agents Chemother. 2016;61(1):6. PMID: 27821458

47. Zurfluh K, Stephan R, Widmer A, Poirel L, Nordmann P, Nüesch $\mathrm{HJ}$, et al. Screening for fecal carriage of MCR-producing Enterobacteriaceae in healthy humans and primary care patients. Antimicrob Resist Infect Control. 2017;6(28):28. https://doi.org/10.1186/s13756-017-0186-Z PMID: 28316780

48. Lu X, Hu Y, Luo M, Zhou H, Wang X, Du Y, et al. MCR-1.6, a New MCR variant carried by an IncP plasmid in a colistinresistant Salmonella enterica Serovar Typhimurium isolate from a healthy individual. Antimicrob Agents Chemother. 2017;61(5):e02632-16-13.

49. Wang Y, Tian GB, Zhang R, Shen Y, Tyrrell JM, Huang X, et al. Prevalence, risk factors, outcomes, and molecular epidemiology of mcr-1-positive Enterobacteriaceae in patients and healthy adults from China: an epidemiological and clinical study. Lancet Infect Dis. 2017;17(4):390-9. https://doi. org/10.1016/S1473-3099(16)30527-8 PMID: 28139431

50. Zhang X-F, Doi Y, Huang X, Li H-Y, Zhong L-L, Zeng K-J, et al. Possible transmission of mcr-1-harboring Escherichia coli between companion animals and human. Emerg Infect Dis. 2016;22(9):1679-81. https://doi.org/10.3201/eid2209.160464 PMID: 27191649

51. Zhang R, Huang Y, Chan EW, Zhou H, Chen S, Zhang R, et al. Dissemination of the $\mathrm{mcr}-1$ colistin resistance gene. Lancet Infect Dis. 2016;16(3):291-2. https://doi.org/10.1016/S14733099(16)00062-1 PMID: 26973306

52. Chen K, Chan EW, Xie M, Ye L, Dong N, Chen S. Widespread distribution of mcr-1-bearing bacteria in the ecosystem, 2015 to 2016. Euro Surveill. 2017;22(39):17-00206.

53. Gröndahl-Yli-Hannuksela K, Lönnqvist $E$, Kallonen $T$, Lindholm L, Jalava J, Rantakokko-Jalava K, et al. The first human report of mobile colistin resistance gene, mcr-1, in Finland. APMIS. 2018;126(5):413-7. https://doi.org/10.1111/apm.12834 PMID: 29696722

54. Servicio Nacional de Sanidad Agropecuaria e Inocuidad Alimentaria (SENASAG). [National Service of Agricultural Health and Food Safety]. Registro de Productos de Uso Veterinario e Insumos Pecuarios. [Registration of Products for Veterinary Use and Livestock Supplies]. Bolivia: SENASAG; 2018. Spanish. Available from: http://190.129.48.189/egp/ productosVeterinarios.html

\section{License and copyright}

This is an open-access article distributed under the terms of the Creative Commons Attribution (CC BY 4.0) Licence. You may share and adapt the material, but must give appropriate credit to the source, provide a link to the licence, and indicate if changes were made.

This article is copyright of the authors or their affiliated institutions, 2018. 